\title{
Article \\ Study of Physico-Chemical Interactions during the Production of Silver Citrate Nanocomposites with Hemp Fiber
}

\author{
Alexandru Cocean ${ }^{1}$, Iuliana Cocean ${ }^{1}$, Georgiana Cocean ${ }^{1,2}$, Cristina Postolachi ${ }^{1}$, Daniela Angelica Pricop ${ }^{3}$, \\ Bogdanel Silvestru Munteanu ${ }^{3}$, Nicanor Cimpoesu ${ }^{1,4}$ and Silviu Gurlui ${ }^{1, *}$
}

1 Atmosphere Optics, Spectroscopy and Laser Laboratory (LOASL), Faculty of Physics, Alexandru Ioan Cuza University of Iasi, 11 Carol I Bld, 700506 Iasi, Romania; alexcocean@yahoo.com (A.C.); iulianacocean@hotmail.com (I.C.); cocean.georgiana@yahoo.com (G.C.); tina.postolaki@gmail.com (C.P.); nicanornick@yahoo.com (N.C.)

2 Rehabilitation Hospital Borsa, 1 Floare de Colt Street, 435200 Borsa, Romania

3 Faculty of Physics, Alexandru Ioan Cuza University of Iasi, 11 Carol I Bld, 700506 Iasi, Romania; daniela.a.pricop@gmail.com (D.A.P.); msbogdanel18@yahoo.com (B.S.M.)

4 Faculty of Material Science and Engineering, Gheorghe Asachi Technical University of Iasi, 59A Mangeron Bld, 700050 Iasi, Romania

* Correspondence: sgurlui@uaic.ro

check for updates

Citation: Cocean, A.; Cocean, I.; Cocean, G.; Postolachi, C.; Pricop, D.A.; Munteanu, B.S.; Cimpoesu, N.; Gurlui, S. Study of Physico-Chemical Interactions during the Production of Silver Citrate Nanocomposites with Hemp Fiber. Nanomaterials 2021, 11, 2560. https://doi.org/10.3390/ nano11102560

Academic Editor: Alexey Pestryakov

Received: 5 September 2021

Accepted: 26 September 2021

Published: 29 September 2021

Publisher's Note: MDPI stays neutral with regard to jurisdictional claims in published maps and institutional affiliations.

Copyright: (c) 2021 by the authors. Licensee MDPI, Basel, Switzerland. This article is an open access article distributed under the terms and conditions of the Creative Commons Attribution (CC BY) license (https:// creativecommons.org/licenses/by/ $4.0 /)$.

\begin{abstract}
In the study presented in this paper, the results obtained by producing nanocomposites consisting of a silver citrate thin layer deposited on hemp fiber surfaces are analyzed. Using the pulsed laser deposition (PLD) method applied to a silver target with impurities of nickel and iron, the formation of the silver citrate film is performed in various ways and the results are discussed based on Fourier Transform Infrared (FTIR) and Scanning Electron Microscopy coupled with Energy Dispersive X-ray (SEM-EDX) spectroscopy analyses. A mechanism of the physico-chemical processes that take place based on the FTIR vibrational modes and the elemental composition established by the SEM-EDS analysis is proposed. Inhibition of the fermentation process of Saccharomyces cerevisae is demonstrated for the nanocomposite material of the silver citrate thin layer, obtained by means of the PLD method, on hemp fabric. The usefulness of composite materials of this type can extend from sensors and optoelectronics to the medical fields of analysis and treatment.
\end{abstract}

Keywords: nanocomposites; pulsed laser deposition

\section{Introduction}

Composite materials, based on texturized textile fibers-as a reinforcing phase, on which silver films are deposited as a continuous phase (matrix) - are made for use in medical devices and also for other applications where an ionic state of silver $\left(\mathrm{Ag}^{+}\right)$is required.

The aim of the experimental procedures presented in this work is to study if, during the pulsed laser deposition (PLD) process, the interaction of citric acid with the ablated silver, in its final plasma stage before hitting the support, and under vacuum chamber conditions, could lead to a chemical reaction that results in the formation of citrate. It is known that silver does not react with citric acid unless one of the reactants is in an ionic state (inorganic compounds of silver, such as $\mathrm{AgNO}_{3}$, would enter into a reaction with citric acid, or sodium citrate would enter into a reaction with silver). Moreover, silver does not react with cellulose in its metallic state. In order to react with cellulose, "silver seeds", i.e., silver nitrate $\left(\mathrm{AgNO}_{3}\right)$, and reagents are required [1]. Other methods utilized for producing silver nanoparticle synthesis in an ionic state, for medical purposes, are based on so-called "green synthesis", where different biological organisms or extracts of those participate in a photochemical or chemical process [2-8]. Plasma reduction is another method used to synthesize Ag nanoparticles and Pt nanoparticles for further applications in dye-sensitized solar cells $[9,10]$. 
The impetus of this research, involving the production of compounds in which silver is in an ionic state, derives from its proven benefits regarding its antibacterial and antifungal properties. Researchers are also concerned with possible applications of gold nanoparticles in cancer treatment, where gold nanoparticles in an ionic state are supposedly the active form against cancer cells. In this respect, synthesis of gold nanoparticles has been achieved in the form of gold citrate but also as gold ionic bonded to polymers such as polyethylene imine [11]. Solar-driven water evaporation could be another application of such developed materials [12,13].

In the general context of interest for the study of noble metal nanoparticles, the method presented in this paper proposes both a new method of producing silver citrate embedded in a composite of the hemp-reinforcing phase, and a model of the physicochemical mechanism of the process that takes place during, and under the conditions of, the pulsed laser deposition.

\section{Materials and Methods}

Pulsed laser deposition (PLD) was performed on the installation in the Atmosphere Optics, Spectroscopy and Lasers Laboratory [14] using the YG 981E/IR-10 laser system, with the parameters $\tau=10 \mathrm{~ns}$ pulse width, $\lambda=532 \mathrm{~nm}$ wavelength, $\alpha=45^{\circ}$ incident angle and $v=10 \mathrm{~Hz}$ pulse repetition time and $3 \cdot 10^{-2}$ Torr pressure, in the deposition chamber (Figure 1). The target subject for ablation (Figure 2) was made of silver with iron and nickel impurities. It was produced from jewelry scraps by means of mechano-thermic processes and chemical cleaning with $99.9 \%$ tetra borate $\left(\mathrm{Na}_{2} \mathrm{~B}_{4} \mathrm{O}_{7} \cdot 10 \mathrm{H}_{2} \mathrm{O}\right)$ and $99 \%$ sodium borohydride $\left(\mathrm{NaBH}_{4}\right)$ to convert silver from the ionic to the atomic state $[15,16]$ followed by treatment with baking soda as a catalyst $\left(\mathrm{NaHCO}_{3} 99.5 \%\right)$ in the presence of aluminum foil in order to remove sulfur from the silver sulfide $\left(\mathrm{Ag}_{2} \mathrm{~S}\right)$.

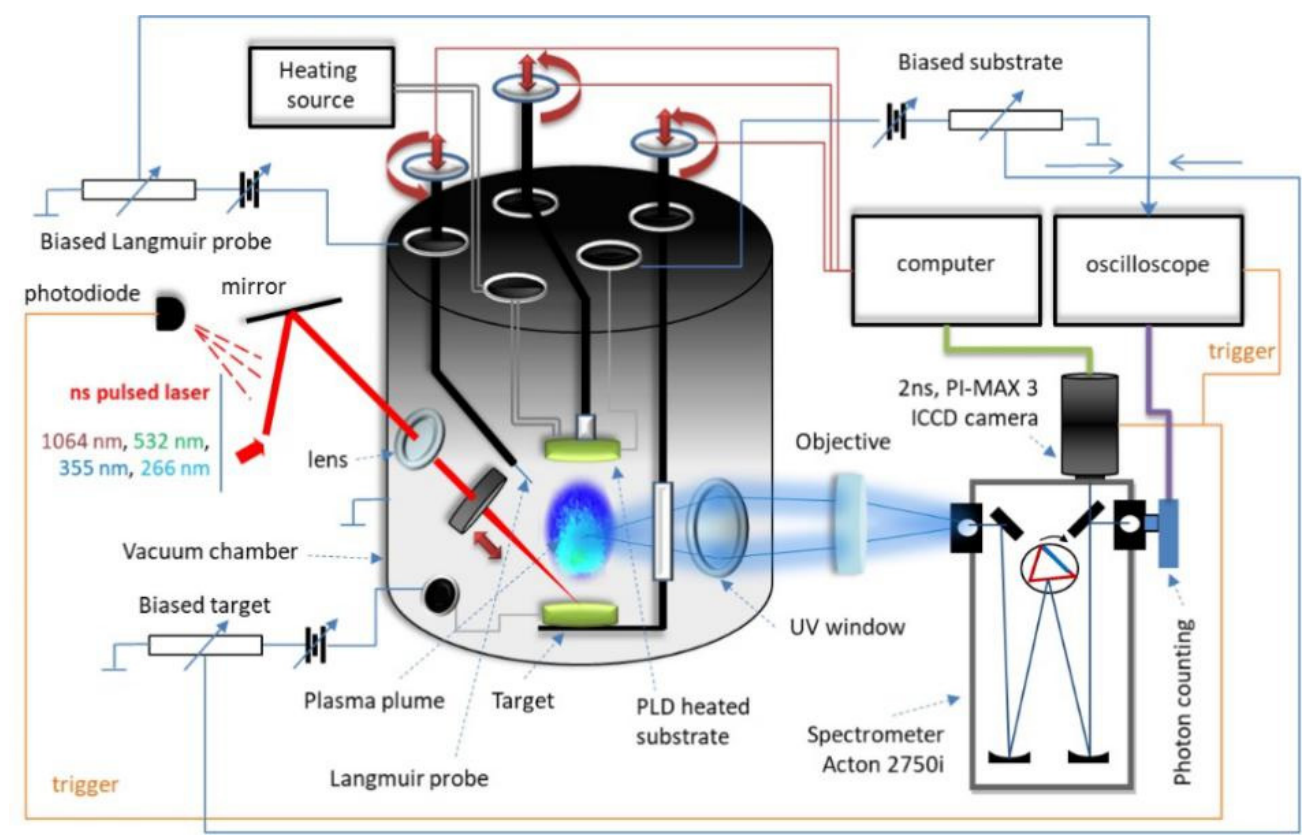

Figure 1. Experimental installation for PLD and LIBS in the Atmosphere Optics, Spectroscopy and Lasers Laboratory (http:/ / spectroscopy.phys.uaic.ro. Accessed on 4 September 2021). 


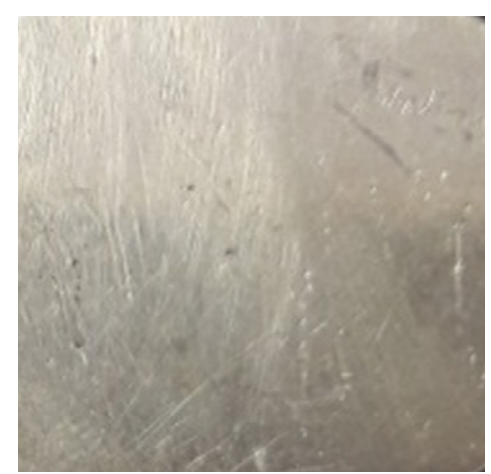

(a)

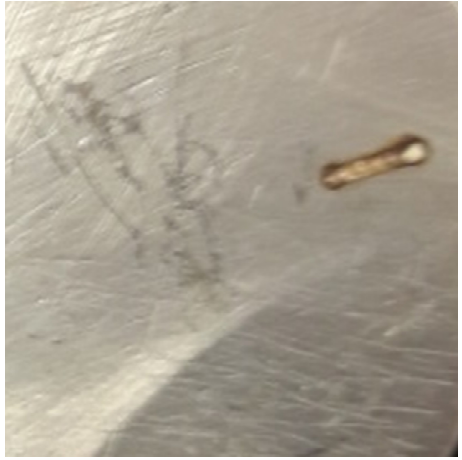

(b)

Figure 2. Silver target: (a) before irradiation; (b) after laser ablation during PLD processes.

The experimental studies refer to the physico-chemical interaction of plasma plume with the substrate containing citric acid. For that purpose, a total of three samples were produced, as follows:

- The film deposition on hemp fabric is noted as sample $D$ (Ag Film/Hemp).

- The next film was deposited on a hemp fabric impregnated with supersaturated aqueous citric acid solution to form composite materials for further applications; this is referred to as sample $E(\mathrm{Ag}$ Film/CA/Hemp).

- Finally, silver film deposition was performed on a layer of citric acid applied as a supersaturated aqueous citric acid solution on a glass slab; this is denoted as sample $F$ (Ag Film/CA/Glass).

The fabrics used as supports are noted as follows: HTND—the hemp twill fabric (natural); HTNS - the hemp twill fabric (natural) impregnated with citric acid solution.

Pulsed laser deposition was performed with laser energy of $150 \mathrm{~mJ}$ on a spot with a $168 \mu \mathrm{m}$ average standard deviation, with a distance target support of $2 \mathrm{~cm}$. The deposition time was $30 \mathrm{~min}$ for $18 \times 10^{4}$ pulses, the number of pulses necessary for obtaining a consistent silver layer [17].

A test to demonstrate the functional property of the new nanocomposite material, Ag-CA-HMP, related to inactivation of the microorganisms, was conducted using dry baker's yeast (Saccharomyces cerevisiae). Samples of hemp fabric, hemp fabric coated with a silver layer and hemp fabric coated with a silver citrate layer, obtained using the PLD method as described in the study presented herein, were placed on three glass slabs of $22 \mathrm{~mm} \times 22 \mathrm{~mm}$ size, while one glass slab was used as a reference $(R)$ or for the blind test. Each of the four glass slabs was placed in a different Petri dish. Quantities of $20 \mathrm{mg}$ of yeast mixed with $10 \mathrm{mg}$ of sugar were placed on the center of each sample and $0.5 \mathrm{~mL}$ of distilled water, at $45{ }^{\circ} \mathrm{C}-50{ }^{\circ} \mathrm{C}$, was added on the mixture of yeast and sugar using a pipette. The samples obtained this way were named as follows:

- 1-Y-active (yeast mixture on the glass slab or blind sample).

- $\quad 2-Y-H M P$ (the yeast mixture on hemp fabric sample).

- $\quad 3-Y-A g-H M P$ (the yeast mixture on the silver layer deposited on the hemp fabric).

- $\quad 4-Y-A g-C A-H M P$ (the yeast mixture on the silver citrate layer deposited on the hemp fabric).

The reference or blind sample was noted as $R-Y-D R Y$.

The surfaces and the foaming bubbles of $\mathrm{CO}_{2}$ were measured in pixels using the Toup View software.

\section{Results and Discussions}

\subsection{Target Initial Chemical Composition}

After the preparatory steps of the target, EDX analysis showed a composition, in atomic percentages, of $81.84 \%$ Silver, $17.40 \%$ Nickel, and $0.76 \%$ iron in some areas; $88.26 \%$ Silver, $10.32 \%$ Nickel, $0.44 \%$ iron in other areas; and even $100 \%$ Silver in some areas. The 
composition demonstrated a non-homogenous distribution of the impurities through the silver matrix of the target, which is consistent with the usual conditions of manufacturing where materials of pure elements are not used due to their high cost and difficulties involved in purifying them, as well as the special storage conditions needed in order to avoid contamination/impurification.

\subsection{Physico-Chemical Processes of Ablation and Redisposition on the Target}

Analyzing the ablated area on the target after it was used in the PLD process, an important increase in iron and nickel was noticed compared with the results obtained before ablation. Thus, the elemental compositions of two areas, of $0.053 \mathrm{~mm}^{2}$ each, that were analyzed at the center of the target after ablation (Figure $3 \mathrm{~b}, \mathrm{c}$ ) were found as being of $64.56 \%$ Silver, $27.01 \%$ Nickel, $8.43 \%$ Iron and $77.20 \%$ Silver, and of $17.56 \%$ Nickel, $5.20 \%$ Iron, respectively. The detected elements were evidenced by the EDS spectrum presented in Figure 4. The increase in $\mathrm{Ni}$ and $\mathrm{Fe}$ atoms on the ablated area of the target was the result of different processes and phenomena during ablation such as re-deposition (Figure 3a-c) of the lighter elements (atomic mass, $\mathrm{A}$, and atomic number, $\mathrm{Z}$, of each component being ${ }_{28}^{58.69} \mathrm{Ni}$ where $\mathrm{A}_{\mathrm{Ni}}=58.69,{ }_{26}^{55.845} \mathrm{Fe}$ where $\mathrm{A}_{\mathrm{Fe}}=26$ and ${ }_{47}^{108} \mathrm{Ag}$ where $\mathrm{A}_{\mathrm{Ag}}=108$ ) that may have been due to their elastic collision with heavier atoms, ions and clusters, but also due to other perturbing phenomena including, but not limited to, the influence of electromagnetic fields on the charged particles (ions). Preferential Silver ablation was indicated with increase in $\mathrm{Ni}$ and Fe in the elemental composition of the ablated area, which is important for the quality of the deposited thin film.

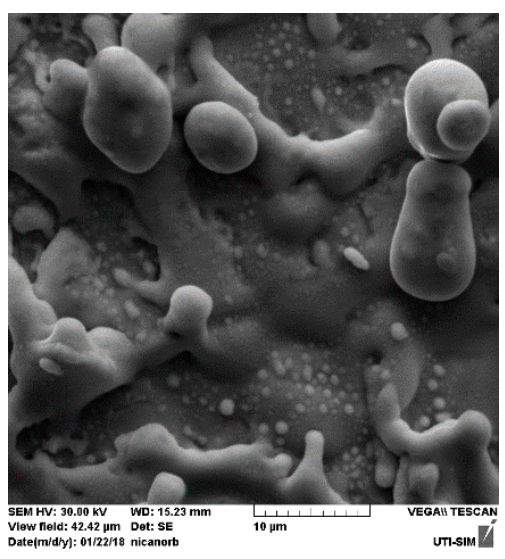

(a)

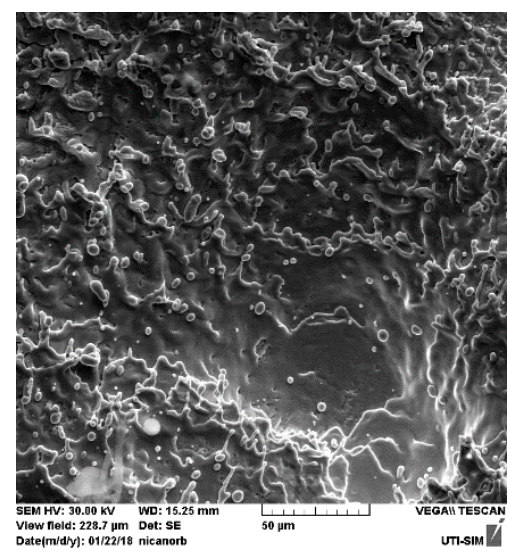

(b)

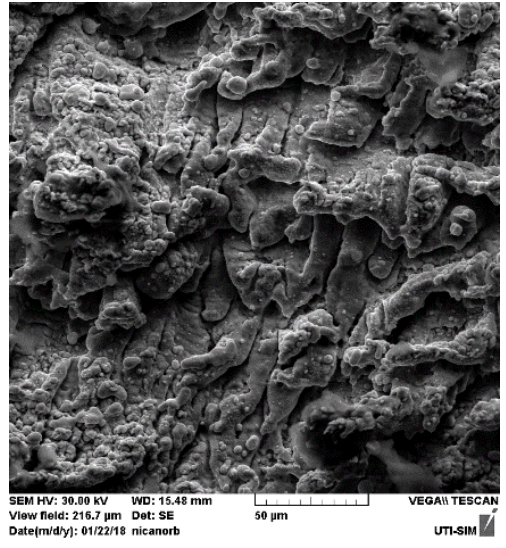

(c)

Figure 3. SEM images on ablated zone of the target with re-deposition structures: 5 kx magnitude (a); 1 kx magnitude (b,c).

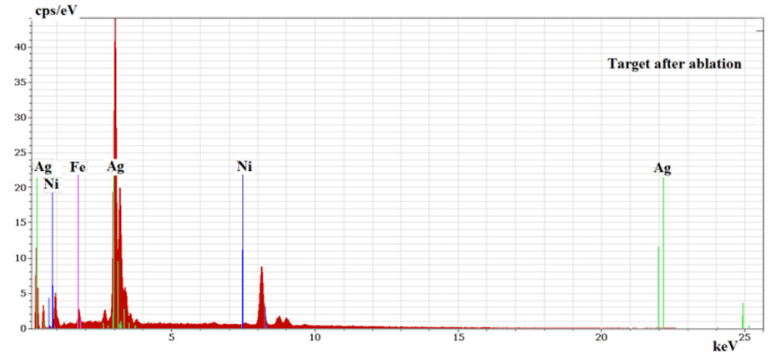

Figure 4. EDX spectrum of the target after ablation.

In the SEM images of Figure 3a-c, the droplets of the re-deposited material can be noticed on the ablated area. 


\subsection{Physico-Chemical Interaction of Silver Plume with the Citric Acid Substrate}

The SEM images $(500 \times$ magnifying) of the three Silver film deposition samples are presented in Figure 5. The silver layer was not only deposited on the fabric surface. It penetrated through the interstices between the twisted fibers that formed the yarns from the fabric texture. In this way, the deposition produced a composite structure with new properties. The ionic state of the silver was the intended goal due to its antibacterial and antifungal properties and, for that reason, the study of the interaction of silver plasma plume with the citric acid from the support was important.

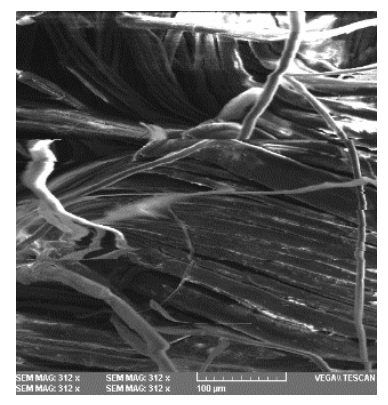

(a)

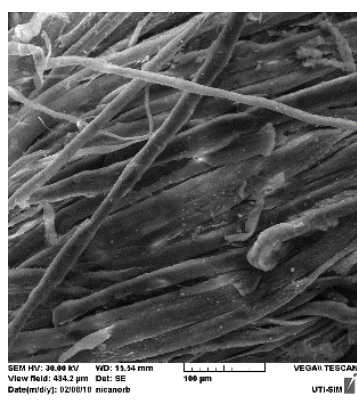

(b)

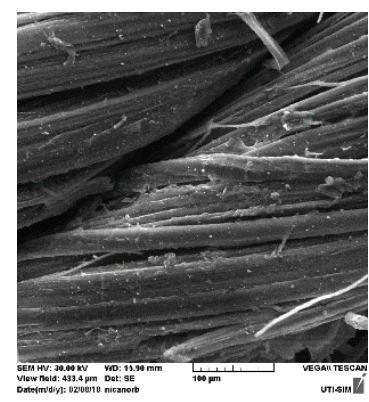

(c)

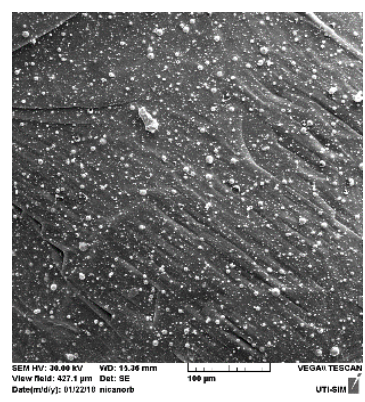

(d)

Figure 5. SEM images $500 \mathrm{x}$ of the samples (a) Hemp fabric used as support for pulsed laser deposition; (b) Sample D (Ag Film/Hemp); (c) Sample E (Ag Film/CA/Hemp); (d) Sample F (Ag Film/CA/Glass).

The images in Figure 5 evidence the droplets of silver resulted during the laser deposition. EDS analysis showed an elemental composition on the thin layers as presented in Table 1 and in the spectra of Figure $6 \mathrm{a}-\mathrm{c}$. The analyzed areas were of $0.185 \mathrm{~mm}^{2}$ on the surfaces presented in Figure 5b-d) for data in Table 1.

Table 1. Elemental composition of the samples: Ag Film/Hemp (D); Ag Film/CA/Hemp (E); Ag Film/CA/Glass (F).

\begin{tabular}{ccccccc}
\hline \multirow{2}{*}{ Element } & \multicolumn{3}{c}{ Norm. wt.\% } & \multicolumn{3}{c}{ Norm. at.\% } \\
\cline { 2 - 8 } & $\begin{array}{c}\text { Sample (D) Ag } \\
\text { Film/ Hemp }\end{array}$ & $\begin{array}{c}\text { Sample (E) Ag } \\
\text { Film/CA/Hemp }\end{array}$ & $\begin{array}{c}\text { Sample (F) Ag } \\
\text { Film/ CA/Glass }\end{array}$ & $\begin{array}{c}\text { Sample (D) Ag } \\
\text { Film/ Hemp }\end{array}$ & $\begin{array}{c}\text { Sample (E) Ag } \\
\text { Film/CA/Hemp }\end{array}$ & $\begin{array}{c}\text { Sample (F) Ag } \\
\text { Film/ CA/Glass }\end{array}$ \\
\hline Oxygen & 76.46 & 76.98 & 52.47 & 82.47 & 82.90 & 86.98 \\
\hline Silver & 10.72 & 10.41 & 41.06 & 1.71 & 1.66 & 10.09 \\
\hline Carbon & 10.58 & 10.33 & - & 15.20 & 14.82 & - \\
\hline Copper & 2.23 & 2.28 & - & 0.60 & 0.62 & - \\
\hline Nickel & - & - & 6.46 & - & 100 & 2.92 \\
\hline & 100 & 100 & 100 & 100 & 100 \\
\hline
\end{tabular}

In the elemental composition of the samples $\mathrm{D}$ and $\mathrm{E}$, copper and carbon belong to the hemp fabric.

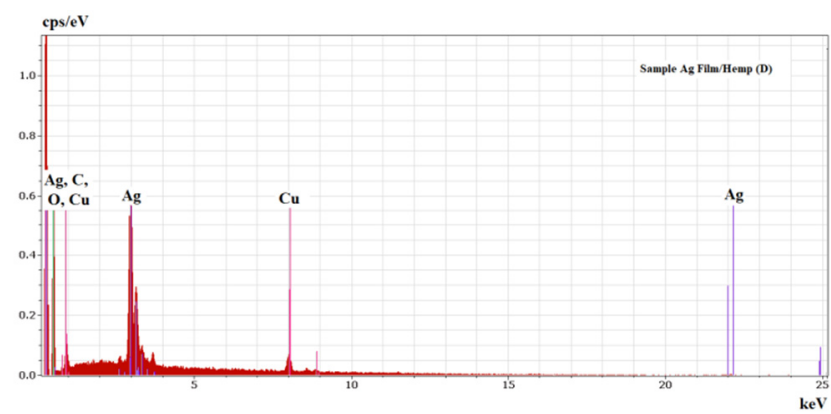

(a)

Figure 6. Cont. 


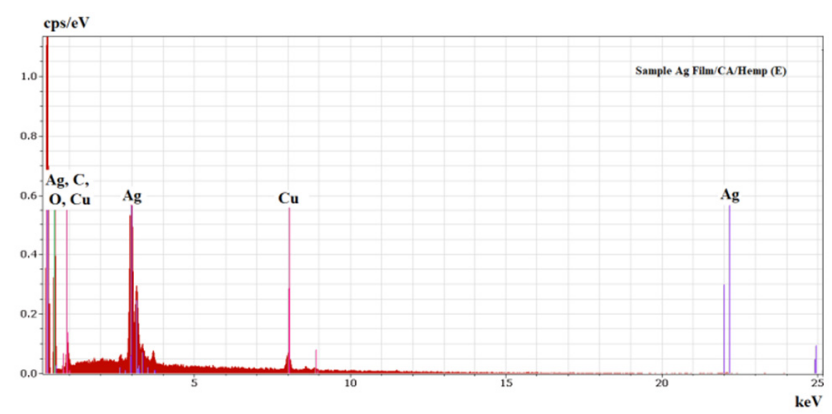

(b)

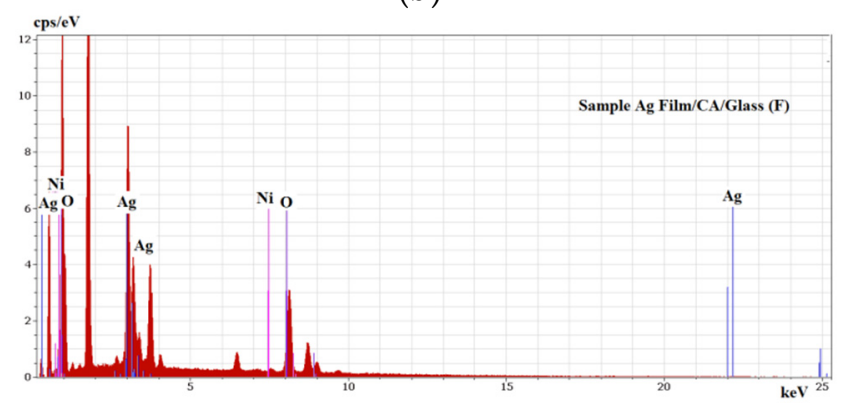

(c)

Figure 6. EDS spectra of the thin layers obtained by PLD: sample Ag Film/Hemp (D) (a); sample Ag Film/CA/Hemp (E) (b); sample Ag Film/CA/Glass (F) (c).

The PLD technique is based on laser ablation when the solid material of the target is transformed into liquid, gas and plasma. Plasma, also known as ionized gas [18-26], is a state of matter where ions, electrons, atoms and clusters exist at the same time. The predominant content in the Silver of the deposited thin film is noted in Table 1 This is in good accordance with the results of elemental composition of the ablated area on the target. It implies that the silver ions should arrive on the support surface and react with the citric acid. Because some of the silver was already derived from the ablation that occurred in liquid state, as per the temperature plots obtained from the COMSOL simulation of silver ablation and depositions shown in the work of A. Cocean et al., 2017 [27], the reaction rate was not expected to be high. Nevertheless, other phenomena can improve the active state of the film and increase its predisposition to subsequent reactions when in contact with biological agents such as bacteria and fungi. Regardless, this was not the experimental subject for this study, but it was where the idea started. Therefore, in order to determine whether the reaction took place, the powder of the deposited layers was collected by scraping it off the surface of the samples, and the FTIR results are presented in Figure 7. In order to avoid the possibility that silver ions could occur from oxidized areas or from $\mathrm{Ag}_{2} \mathrm{~S}$ that may form, in time, on the target surface when in contact with the atmosphere, borax was incorporated on the target (as presented in the Section 2). It followed that silver ions from oxides and/or sulfides had been converted into atoms before the PLD process, but also during PLD if any remaining oxygen traces were present in the deposition chamber. This provides further evidence that the only source of silver ions that will react with the citric acid is the plasma obtained via ablation during which ions, atoms and clusters coexist. For a better evaluation of the FTIR spectra of the samples that were experimentally obtained, they were also compared with the spectra of the hemp fabrics used as supports for silver deposition, namely HTND (hemp fabric) and HTNS (hemp fabric impregnated with the supersaturated citric acid aqueous solution). The FTIR spectra (Figure 7) show the changes that citric acid undergoes as a result of silver deposition. The transformation of carboxyl groups into carboxylate ions can be observed in the FTIR spectra, and the formation of silver citrate is indicated. 


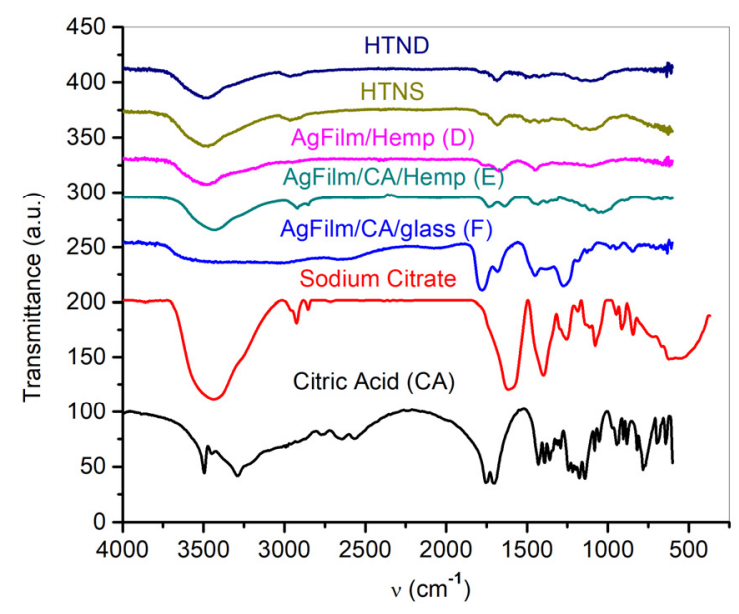

Figure 7. Comparison of the FTIR spectra of samples D (AgFilm/Hemp), E (AgFilm/CA/Hemp) and $\mathrm{F}$ (AgFilm/CA/glass), and the sodium citrate and citric acid (CA).

In this regard, for both types of hydroxyl groups assigned to carboxyl from citric acid (free: $3500 \mathrm{~cm}^{-1}$; H-bounded: $3283 \mathrm{~cm}^{-1}[28,29]$ ), there is evidence that they were transformed into ionized $\mathrm{COO}^{-}$groups, which were involved in ionic bonds with $\mathrm{Ag}^{+}$, as indicated by the carbonyl bands from $1638 \mathrm{~cm}^{-1}$ to $1760 \mathrm{~cm}^{-1}$ [28,29].

The bands from about $3500 \mathrm{~cm}^{-1}$ were the alcoholic groups $[28,29]$ of the citric acid spectrum (CA), but they were also found in the sample of PLD film spectra for citrate when the peak became broader due to hydrogen bonding. This caused the silver ions from the plasma that was produced via ablation, that still existed when arriving on the substrate surface, to enter into a reaction with the citric acid, and thus, may have formed trisilver citrate as well as also mono- and disilver citrate (Figure 8). However, the physico-chemical process was more complex than only a citric reaction with silver plasma ions. The presence of intermolecular H-bonds between the hydroxyl groups of the citrate is indicated in the broad band at $3500 \mathrm{~cm}^{-1}$ in the sample E spectrum. Furthermore, it has been established that the partially ionized oxygen from the carbonyl groups will enter into hydrogen bonds with hydroxyl groups from other molecules, but also intramolecular bonds, as the peak from $1638 \mathrm{~cm}^{-1}$ could indicate [28,29]. H-bonding could also have occurred between the citrate and cellulose (Figure $9 \mathrm{~b}$ ). The spectrum of sample $\mathrm{E}$ (hemp impregnated with citric acid before deposition) evidences the formation of citrate. As for the silver that was deposited directly on the citric acid (sample F), the spectrum indicates that some of the citric acid had reacted with silver plasma ions, while some still existed as citric acid, or alternatively, only part of the carboxylic groups had been transformed into carboxylates (Figure 9c).

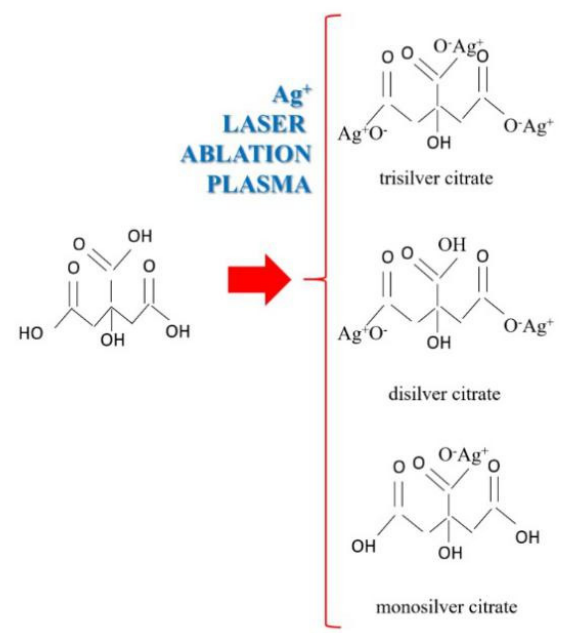

Figure 8. Chemical reaction of citric acid with silver ions from the laser ablation plasma plume. 


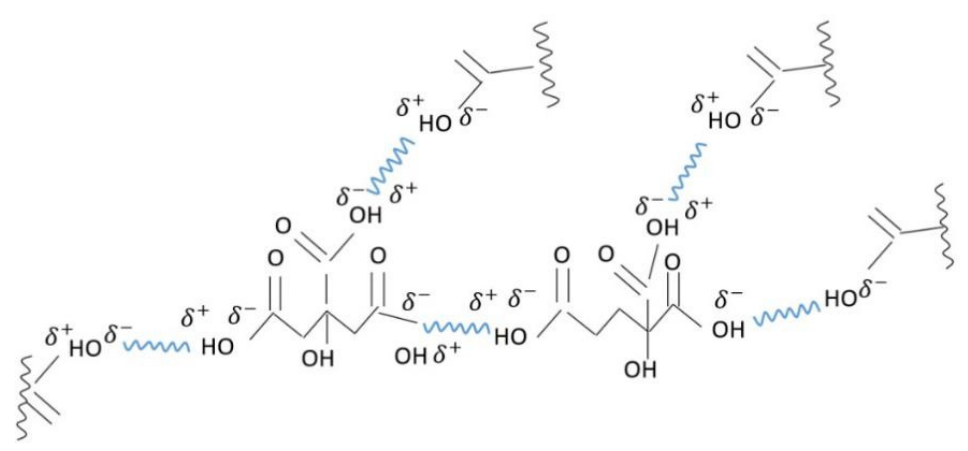

(a)

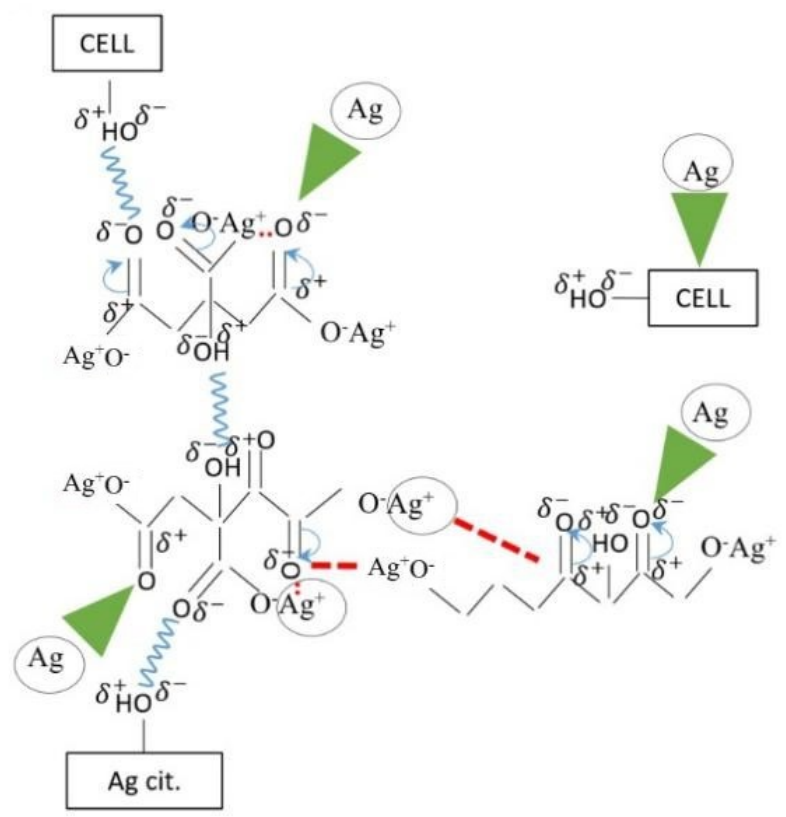

(b)

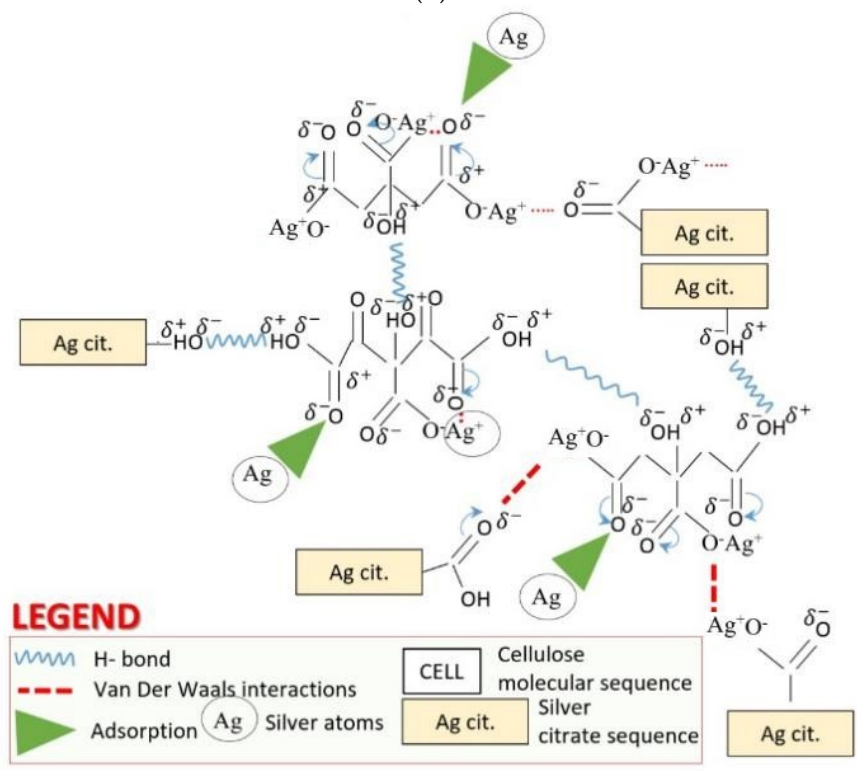

(c)

Figure 9. The reactions, namely the intermolecular and intramolecular interactions, that may occur upon the impact of silver plasma with the substrate surface containing citric acid: (a) hydrogen bonding in citric acid; (b) sequence of intermolecular H-bonding, inter- and intramolecular Van Der Waals interactions and Silver atoms' adsorption on citrate and cellulose; (c) sequence of intermolecular Hbonding, inter- and intramolecular Van Der Waals interactions and Silver atoms' adsorption on citrate. 
Due to the environmental conditions in the vacuum chamber, it was possible for a further ionized structure of the silver citrate to form, which may have interacted through ionic and H-bonding and formed aggregates and complex structures, the most evident being for the citrate formed on the glass slab. The very broad band of the F (Ag Film/CA/Glass) spectra between 3560 and $2598 \mathrm{~cm}^{-1}$ indicates that both the carboxyl and carboxylate groups coexisted $[28,29]$, meaning that part of the citric acid was transformed into citrate and part remained as citric acid. The broad band also indicates H-bonds, intermolecular ionic bonds and other intermolecular interactions, such as Van Der Waals interactions. Such a model may be depicted as in Figure 9a-c. Van Der Waals interactions between ionized and/or partially ionized atoms would have taken place in both films (the E-film on the hemp treated with citric acid and the F-film that was deposited on the citric acid). The adsorption of silver atoms on the carbonyl groups was also part of the complex interactions in the thin film system (Figure 9b,c).

The reactions, namely the intermolecular and intramolecular interactions, that may occur upon the impact of silver plasma with the substrate surface containing citric acid are schematically presented in Figures 8 and $9 a-c$. Further studies of this process of interaction between the silver plasma ions and the citric acid molecules during pulsed laser deposition, and its mechanism, may lead to a technique that can produce silver layers that are active against bacteria as well as being useful for other applications where an ionic state of silver and/or other metals is required. As noticed when analyzing the FTIR spectrum for silver deposited, by means of the PLD technique, on the citric acid, not all of the citric acid was transformed into citrate; this was because the quantity of the citric acid was excessive compared to the quantity of silver ions formed in the plasma. Based on this observation, a method to measure the quantity of the ions of metals that arrive on the substrate, and further, a PLD method of "titration", could be developed to analyze different intermediary compounds formed during the travelling of plasma on the path from the target to the substrate.

Regarding the sizes and shapes of the nanoparticles, UV-Vis spectral analysis was performed on sample F (Ag Film/CA/Glass). For the analysis, material was scraped from the upper part of the layer and was deposited on a glass slide (Ag Film/CA/Glass), with care taken not to scrape the glass directly. The material was dissolved in $2 \mathrm{~mL}$ of distilled and deionized water. The distilled and deionized water was used for comparison. Because the amount of material taken from the thin layer for UV-Vis analysis was very small and the dilution was high (imposed by the $2 \mathrm{~mL}$ cuvette volume), the signal obtained for absorption was of low intensity. However, peaks that, in the literature, were assigned to various sizes of silver nanoparticles, as well as silver citrate, can be observed. Thus, the UV-Vis spectrum (Figure 10) shows a succession of $284 \mathrm{~nm}, 353 \mathrm{~nm}, 412 \mathrm{~nm}, 443 \mathrm{~nm}$ peaks and a wide band between $487 \mathrm{~nm}$ and $543 \mathrm{~nm}$. The peak at $284 \mathrm{~nm}$ could be related to the formation of $\left(\mathrm{Ag}^{+}\right)_{3} /$ citrate complexes [30], probably in the form of silver clusters and/or ultra-small silver nanoparticles [31]. Furthermore, in the same spectrum, a narrow band at $353 \mathrm{~nm}$ and a wide band between 487 and $543 \mathrm{~nm}$ appeared, possibly caused by the fusion of heated nanoparticles as a result of laser exposure. The spectral footprint of the fused nanoparticles is suggested by the wide band (between 487 and $543 \mathrm{~nm}$ ) of the longitudinal oscillation mode of the surface plasmon and the narrow band at $353 \mathrm{~nm}$ of the transverse oscillation mode [32,33]. The fused nanoparticle formation could also be assigned to the broader bands, at $3500 \mathrm{~cm}^{-1}$, of the FTIR spectra of samples E (AgFilm/CA/Hemp) and $\mathrm{F}$ (AgFilm/CA/Glass), but without neglecting other forms of aggregation, such as those described and presented in Figure 9. 


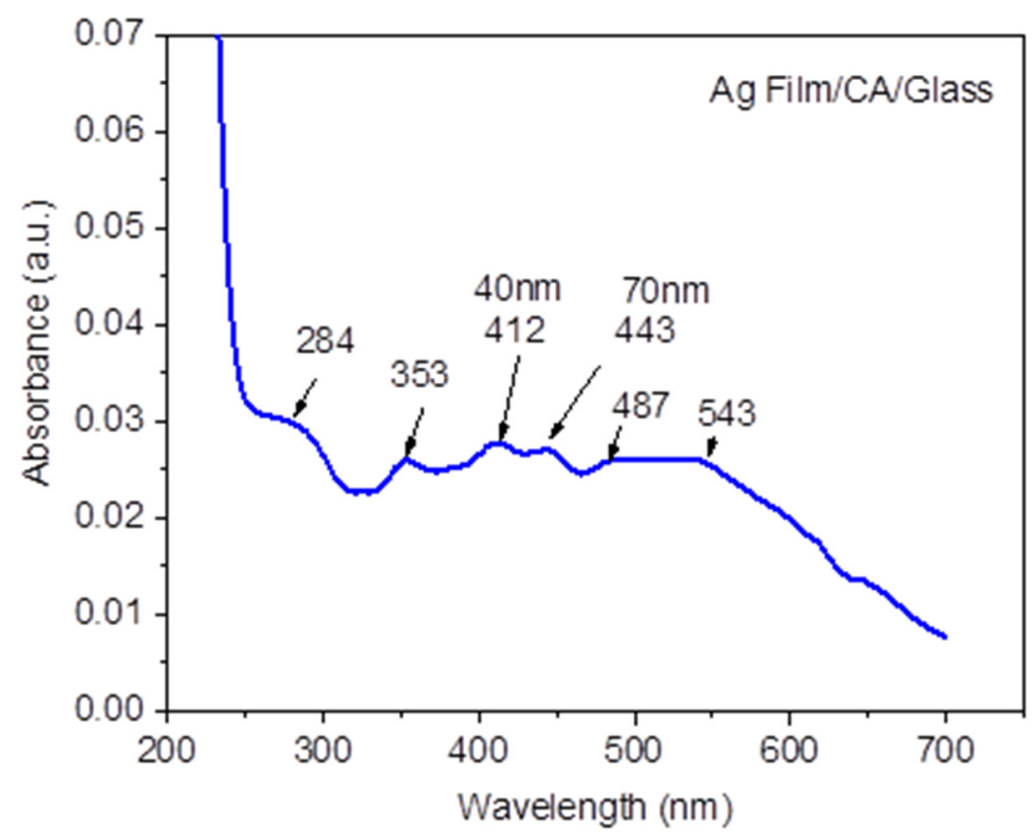

Figure 10. UV-Vis spectrum of sample F (Ag Film/CA/Glass).

Two other peaks at $412 \mathrm{~nm}$ and $443 \mathrm{~nm}$ can be attributed to the formation of triangular nanoparticles, with dimensions of around $40 \mathrm{~nm}$ [34], and nanoparticles with uneven shapes between 60 and $70 \mathrm{~nm}$ [35].

Citrate molecules act as both a capture ligand for silver particles and as a photoreducing agent for silver ions [36,37]. It is known that under the action of light radiation, citrate photoresists silver ions at the surface of previously formed silver seeds. The growth of nanoparticles with different morphologies is due to the rates of citrate reduction on certain faces of silver crystallites [34]. Silver-citrate complexes formed as a result of pulsed laser deposition indicate a possible application of the developed material as an antimicrobial layer [38].

\subsection{Yeast Foaming Test for the New Ag-CA-HMP Material Synthesized by PLD Method}

During the foaming test described in the Section 2, an intense foaming activity was observed on sample 1-Y from the first moment; the yeast on samples 2-Y-HMP and 3-YAg-HMP was less active, while there was no foaming activity on sample 4-Y-Ag-CA-HMP (Figure 11).

1. Y-active

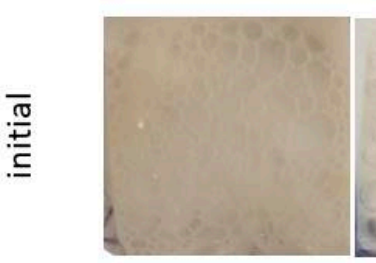

mon
2. Y-HMP

3. Y-Ag-HMP

4. Y-Ag-CA-HMP
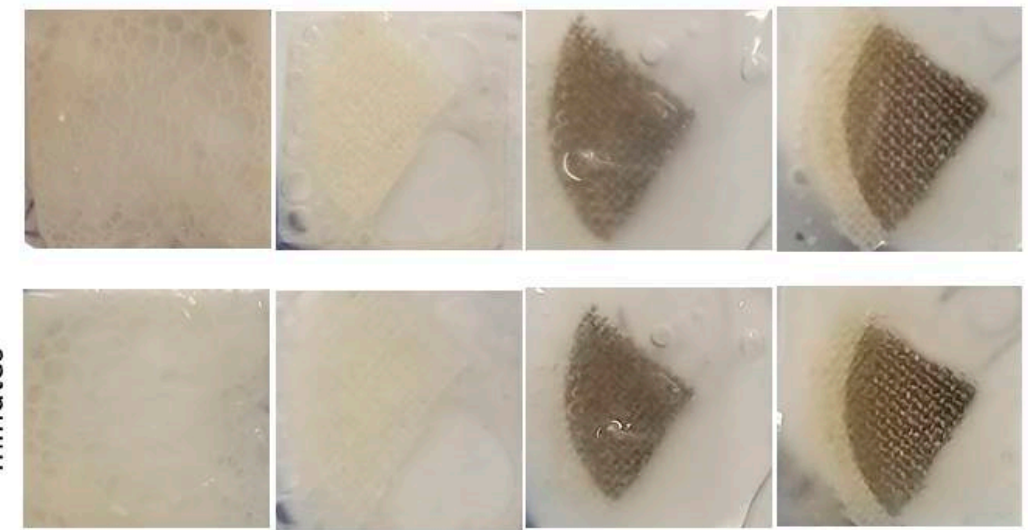

Figure 11. Images of foaming activity initial and after $3 \mathrm{~min}$ from starting the foaming test. 
Based on the measurements of the samples and the dimensions of the glass slabs made using the Toup View software, in addition to the diameters of the $\mathrm{CO}_{2}$ bubbles, the foaming activity (FA\%) and foaming stability (FS\%) were calculated for the initial moment of the foaming test, and at $3 \mathrm{~min}$ from the point at which the foaming test had started. The foaming activity and foaming stability were calculated as follows:

Glass slab area:

$$
A=L \cdot l
$$

The areas of samples 2, 3 and 4 (the samples on the fabric have one quarter of the area of the circles seen in Figure 11):

$$
A=\frac{\pi \cdot R^{2}}{4}=\frac{\pi \cdot D^{2}}{16}
$$

Areas of the bubbles:

$$
a=\pi \cdot r^{2}=\frac{\pi \cdot d^{2}}{4}
$$

The total foam area on each sample as the sum of the areas of the bubbles:

$$
F=\sum_{i=0}^{n} a_{i}
$$

The foaming activity, as a percentage of the foam area from the sample area and from the slab area, respectively:

$$
F A \%=\frac{F}{A} \cdot 100
$$

The foaming stability, as a percentage of the foaming activity after 3 min from the point at which the foaming test was started, derived from the initial foaming activity of

\begin{tabular}{|c|c|c|c|c|c|c|c|}
\hline & \multirow{2}{*}{ Sample } & \multicolumn{2}{|c|}{ FA\% (on Sample Surface) } & \multicolumn{2}{|c|}{ FA\% (on Slab Surface) } & \multirow{2}{*}{$\begin{array}{c}\text { FS\% (on Sample } \\
\text { Surface) }\end{array}$} & \multirow{2}{*}{$\begin{array}{c}\text { FS\% (on } \\
\text { Slab Surface) }\end{array}$} \\
\hline & & Initial & after $3 \mathrm{~min}$ & Initial & after $3 \mathrm{~min}$ & & \\
\hline 1 & Y-active & 89.42 & 9.71 & 89.42 & 9.71 & 12.23 & 12.23 \\
\hline 2 & Y-HMP & 8.14 & 10.12 & 7.86 & 5.80 & 155.97 & 74.09 \\
\hline 3 & Y-Ag-HMP & 7.37 & 6.99 & 3.21 & 2.80 & 86.86 & 74.18 \\
\hline 4 & Y-Ag-CA-HMP & 0.00 & 0.00 & 0.34 & 0.00 & - & 0.00 \\
\hline
\end{tabular}
each sample:

$$
F S \%=\frac{F A_{\text {initial }}(\%)}{F A_{\text {after } 3 \text { minutes }}(\%)} \cdot 100
$$

The results are presented in Table 2 and in Figure 12.

Table 2. Foaming activity (FA\%) and foaming stability (FS\%).

The changes that occurred within 3 min of the initiation of foaming activity among the studied samples, using the surface of each sample and that of the glass slab on which the sample was placed as references, are presented in Figure 12a,b. The variations in foaming stability among the studied samples, using the area of each sample and that of the glass slab, are shown in Figure 13a,b. 


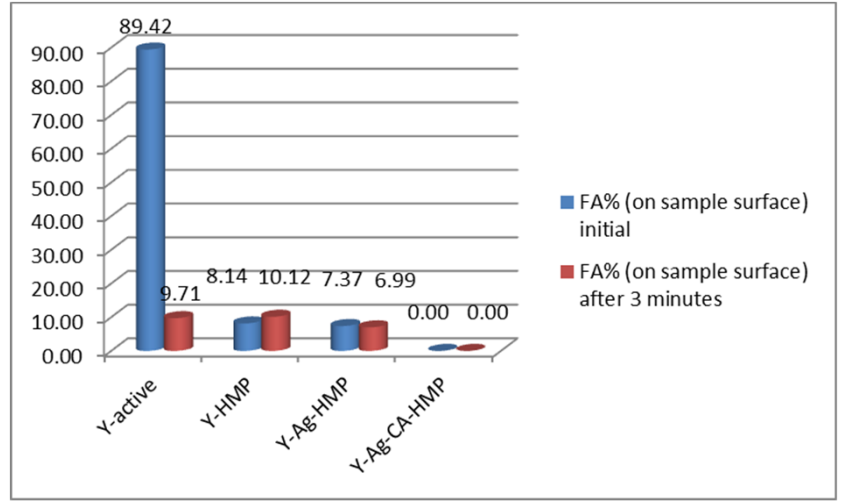

(a)

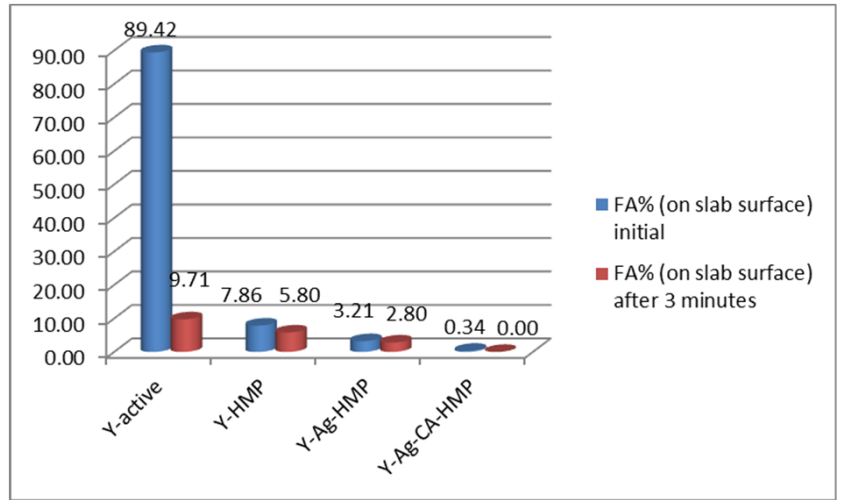

(b)

Figure 12. Comparison of yeast foaming activity (FA\%) on the samples' surfaces (a) and on slab surface (b).

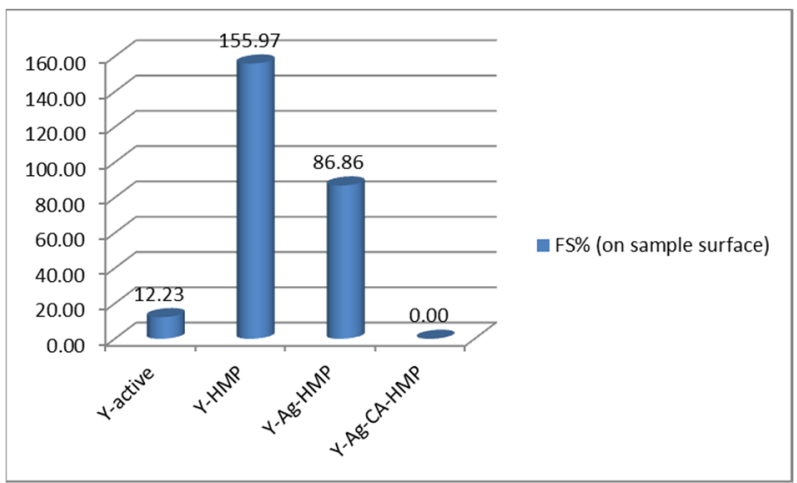

(a)

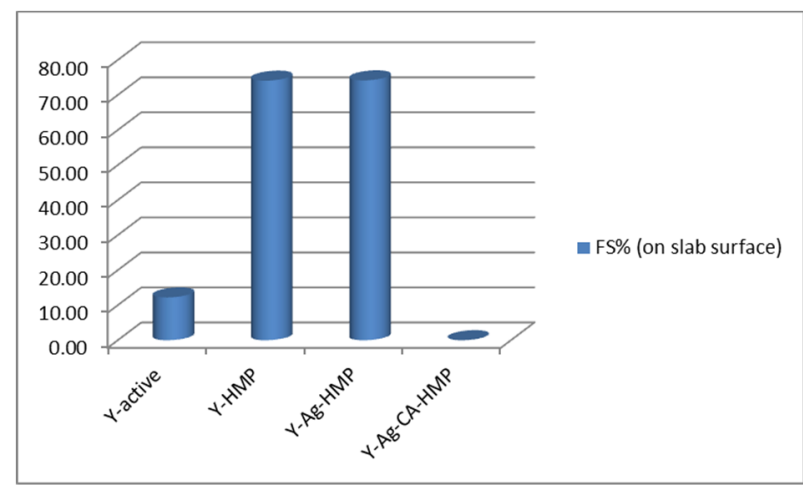

(b)

Figure 13. Comparison of yeast foaming stability (FS\%) on samples' surfaces (a) and on slab surface (b).

The samples that were produced via the foaming test were dried at $25^{\circ} \mathrm{C}$ for $24 \mathrm{~h}$, and each sample was kept in a Petri dish. After drying, yeast material was collected from the glass slab of each sample. Each sample of yeast material was mixed with $\mathrm{KBr}$ in a mortar and, after that, was pressed into a ring and FTIR analysis was performed. The same process was undertaken with the sample of dry yeast that was used in the foaming test. The resulting spectra of the four samples and of the reference sample (dry yeast) are presented in Figure 14a,b.

The peaks that were specific to the FTIR spectrum of the dry yeast sample (Figure 14, Y-DRY) were also found in the spectra of the Y-active, Y-HMP and Y-Ag-HMP samples, with very small variation in terms of their intensity. The $3417 \mathrm{~cm}^{-1}$ band may be assigned to $\mathrm{N}-\mathrm{H}$ stretching in the same range as the $\mathrm{O}-\mathrm{H}$-free and $\mathrm{H}$-bonded samples. The bands assigned to proteins (the band at $1631 \mathrm{~cm}^{-1}$ assigned to CNO stretching and N-H bending in amides I, and the band at $1545 \mathrm{~cm}^{-1}$ assigned to C-N stretching and N-H bending in amides II) $[39,40]$, as well as those assigned to sugars $\left(1057 \mathrm{~cm}^{-1}\right.$ and $908 \mathrm{~cm}^{-1}$; these bands were specific to the cyclic ethers in carbohydrates) $[39,40]$ or nucleic acids, denoted by the band at $1240 \mathrm{~cm}^{-1}$ as per A. Gallichet et al., 2001 [41], do not appear to have been essentially modified in the FTIR spectra of the mentioned samples.

Unlike the other three samples (Y-active, Y-HMP and Y-Ag-HMP), the test conducted the on Y-Ag-CA-HMP sample shows essential changes in the FTIR spectrum (Figure 14, Y-Ag-CA-HMP) compared to the spectrum of the dry yeast, and also in comparison to all other samples (Y-active, Y-HMP and Y-Ag-CA-HMP). In essence, the spectrum of the Y-Ag-CA-HMP sample shows the characteristics of sucrose (table sugar) even if some peaks appear to have overlapped those of yeast, which is also known to contain sugars. 


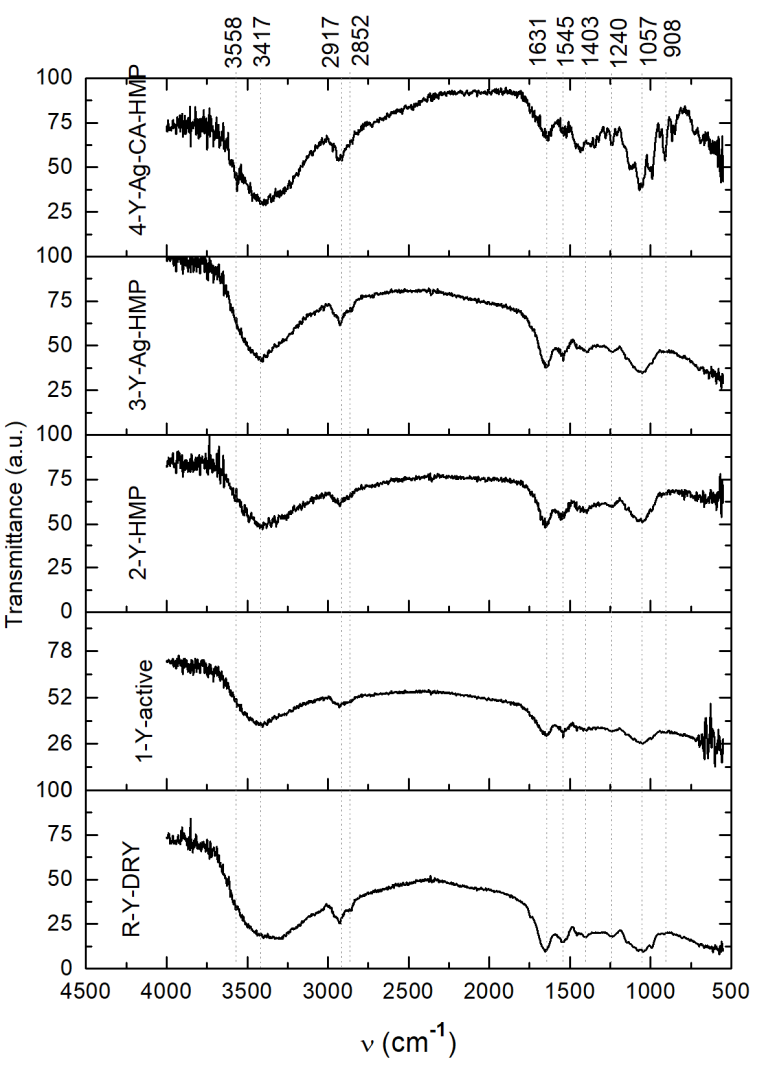

(a)

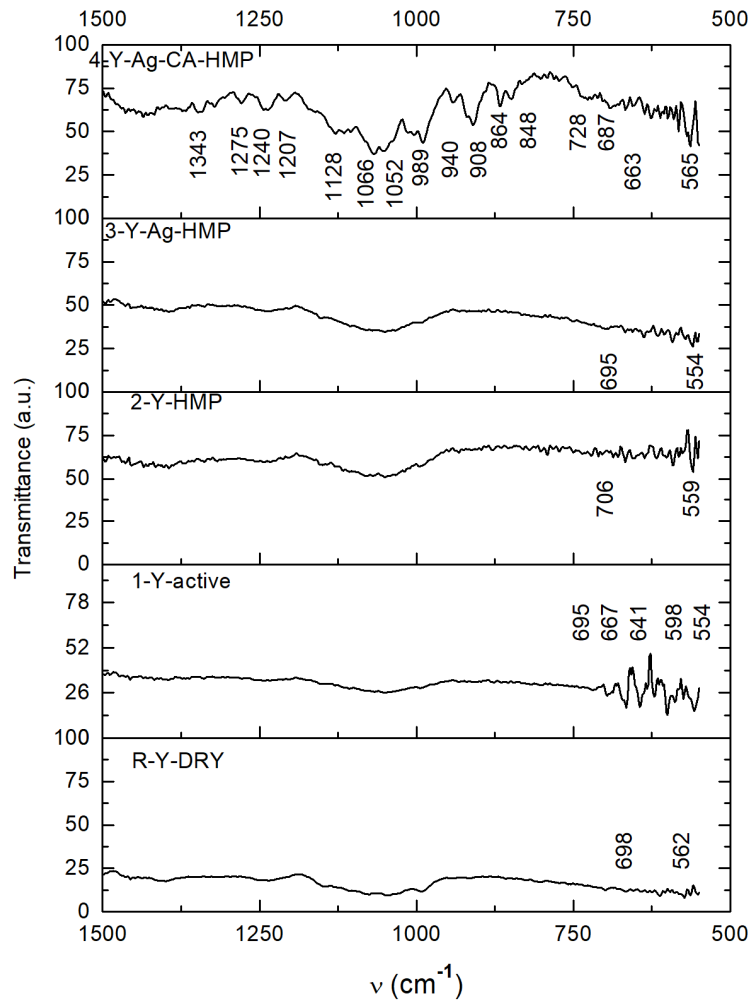

(b)

Figure 14. FTIR spectra of investigated behavior of yeast to different media provided by the analyzed materials (a) and detailed FTIR spectra in the finger-print region of $1500 \mathrm{~cm}^{-1}-500 \mathrm{~cm}^{-1}$ (b).

Of note is the strong and sharp vibrational band from $3558 \mathrm{~cm}^{-1}$, which is specific to the spectrum of sucrose and is attributed to the free $\mathrm{OH}$ groups [41,42].

In the finger-print area of the Y-Ag-CA-HMP sample spectrum, the bands from $1403 \mathrm{~cm}^{-1}, 1343 \mathrm{~cm}^{-1}, 1275 \mathrm{~cm}^{-1}, 1240 \mathrm{~cm}^{-1}, 1207 \mathrm{~cm}^{-1}, 1128 \mathrm{~cm}^{-1}, 1066 \mathrm{~cm}^{-1}, 1052 \mathrm{~cm}^{-1}$, $989 \mathrm{~cm}^{-1}, 940 \mathrm{~cm}^{-1}, 908 \mathrm{~cm}^{-1}, 864 \mathrm{~cm}^{-1}, 848 \mathrm{~cm}^{-1}, 728 \mathrm{~cm}^{-1}, 728 \mathrm{~cm}^{-1}, 680 \mathrm{~cm}^{-1}$ and $663-565 \mathrm{~cm}^{-1}$ are highlighted, and these are assigned to ethers ( $\mathrm{C}-\mathrm{O}-\mathrm{C}$ stretch asymmetric; arC-O-alC) and to related components $[14,28,29]$; these bands can also be found in online databases on sucrose $\left(1427 \mathrm{~cm}^{-1}, 1343 \mathrm{~cm}^{-1}, 1279 \mathrm{~cm}^{-1}, 1240 \mathrm{~cm}^{-1}, 1208 \mathrm{~cm}^{-1}, 1126 \mathrm{~cm}^{-1}\right.$, $1065 \mathrm{~cm}^{-1}, 1049 \mathrm{~cm}^{-1}, 988 \mathrm{~cm}^{-1}, 942 \mathrm{~cm}^{-1}, 908 \mathrm{~cm}^{-1}, 866 \mathrm{~cm}^{-1}, 849 \mathrm{~cm}^{-1}, 732 \mathrm{~cm}^{-1}$, $687 \mathrm{~cm}^{-1}$ and $640-521 \mathrm{~cm}^{-1}$ ) [39,40].

Based on the FTIR spectra shown in Figure 14, the interpretation of the foaming test results presented in Figures 12 and 13, as well as in Table 2, is that the fermentative effect of the yeast (Saccharomyces cerevisiae) on sugar was inactivated by the silver citrate layer that was obtained on the hemp fabric using the PLD technique and the method reported in this paper.

Thus, in the case of the three samples (Y-active, Y-HMP and Y-Ag-HMP), the fermentation of sugar is highlighted both by the $\mathrm{CO}_{2}$ release process that can be observed in the foaming effect that occurred with the generation of the measured gas bubbles (Figures 12 and 13 and Table 2) and by the FTIR spectra, which was similar to that of the initial yeast spectrum. In the case of the Y-Ag-CA-HMP sample (the silver citrate layer deposited on the hemp fabric that we fabricated according to the new method described herein), no $\mathrm{CO}_{2}$ bubbles were released during the foaming test, and in the immediate vicinity, there was only an insignificant amount of initial foaming activity (FA\%) of $0.34 \%$, with $0 \%$ foaming stability (FS\%), at $3 \mathrm{~min}$ from initiation. This is in accordance with the 
FTIR spectrum of sample Y-Ag-CA-HMP, which also shows that the fermentation of sugar did not take place.

\section{Conclusions}

The ionic state of silver is important for the production of composites with antibacterial and antifungal properties for various applications, including medical, but its importance is not limited to them. This study has shown that the PLD technique is suitable for the production of silver citrate as a result of the interaction of the ablation plume with a citric acid substrate or a substrate with citric acid contents. There are also indications resulting from the experiment presented herein that a method of "titration" may be developed in order to determine the quantity of metals ionic state in the plasma plume at different distances from the target, based on specific reactions. The method could be extended to other materials, with the aim of producing silver-based composites for later applications in industry and medicine, as well as for environmental investigations and air and water filtration. The tests and investigations show that the silver citrate that was obtained on the hemp fabric using our new method inactivated the yeast (Saccharomyces cerevisiae), confirming the effect of silver ions on the microorganisms, which, at the very least, inactivated their metabolism. This proves that a new functional material was obtained. Such nanocomposites of the silver citrate layer on the hemp fabric can be useful in processes where fermentation or excessive foaming induced by yeasts needs to be controlled by inhibition processes. Further investigations are needed and will be conducted to study the antimicrobial effect of the new nanocomposite material.

In order to determine the oxidation state of silver during deposition and on the deposited layer, in our further studies, we will consider the development of a method of analysis to be utilized in the deposition chamber. This method is necessary because the analysis would take place without the risk of contamination of the sample as a result of contact with air.

Author Contributions: Conceptualization, A.C., I.C., G.C., C.P. and S.G.; methodology, A.C., I.C., G.C., C.P. and S.G.; software, A.C.; validation, A.C., G.C., S.G., I.C.; formal analysis, G.C., A.C., I.C., S.G., C.P., D.A.P., B.S.M. and N.C.; investigation, A.C., G.C., I.C., S.G., B.S.M., N.C. and D.A.P.; resources, S.G.; data curation, A.C., I.C., G.C., C.P. and S.G.; writing—original draft preparation, A.C., I.C. and S.G.; writing-review and editing, A.C., G.C., I.C. and S.G.; visualization, S.G., A.C., and I.C.; supervision, S.G.; project administration, S.G.; funding acquisition, S.G. All authors have read and agreed to the published version of the manuscript.

Funding: This research was funded by the Ministry of Research, Innovation and Digitization, project FAIR_09/24.11.2020, and by the Executive Agency for Higher Education, Research, Development and Innovation, UEFISCDI, ROBIM, project number PN-III-P4-ID-PCE2020-0332.

Data Availability Statement: Not applicable.

Conflicts of Interest: The authors declare no conflict of interest.

\section{References}

1. Zeng, J.; Tao, J.; Li, W.; Grant, J.; Wang, P.; Zhu, Y.; Xia, Y. A Mechanistic Study on the Formation of Silver Nanoplates in the Presence of Silver Seeds and Citric Acid or Citrate Ions. Chem.-Asian J. 2010, 6, 376-379. [CrossRef]

2. Bera, R.K.; Raj, C.R. A facile photochemical route for the synthesis of triangular Ag nanoplates and colorimetric sensing of $\mathrm{H}_{2} \mathrm{O}_{2}$. J. Photochem. Photobiol. A: Chem. 2013, 270, 1-6. [CrossRef]

3. Butch, C.; Cope, E.D.; Pollet, P.; Gelbaum, L.; Krishnamurthy, R.; Liotta, C.L. Production of Tartrates by Cyanide-Mediated Dimerization of Glyoxylate: A Potential Abiotic Pathway to the Citric Acid Cycle. J. Am. Chem. Soc. 2013, 135, 13440-13445. [CrossRef]

4. Homan, K.A.; Souza, M.; Truby, R.; Luke, G.P.; Green, C.; Vreeland, E.; Emelianov, S. Silver Nanoplate Contrast Agents for In Vivo Molecular Photoacoustic Imaging. ACS Nano 2012, 6, 641-650. [CrossRef]

5. Zhang, L.V.; Brunet, P.; Eggers, J.; Deegan, R.D. Wavelength selection in the crown splash. Phys. Fluids 2010, 22, 122105. [CrossRef]

6. Jyoti, K.; Baunthiyal, M.; Singh, A. Characterization of silver nanoparticles synthesized using Urtica dioica Linn. leaves and their synergistic effects with antibiotics. J. Radiat. Res. Appl. Sci. 2016, 9, 217-227. [CrossRef] 
7. Bagherzade, G.; Tavakoli, M.M.; Namaei, M.H. Green synthesis of silver nanoparticles using aqueous extract of saffron (Crocus sativus L.) wastages and its antibacterial activity against six bacteria. Asian Pac. J. Trop. Biomed. 2017, 7, 227-233. [CrossRef]

8. Karthik, L.; Kumar, G.; Kirthi, A.V.; Rahuman, A.A.; Rao, K.V.B. Streptomyces sp. LK3 mediated synthesis of silver nanoparticles and its biomedical application. Bioprocess Biosyst. Eng. 2013, 37, 261-267. [CrossRef] [PubMed]

9. Dao, V.-D.; Choi, H.-S. Highly-Efficient Plasmon-Enhanced Dye-Sensitized Solar Cells Created by Means of Dry Plasma Reduction. Nanomaterials 2016, 6, 70. [CrossRef]

10. Dao, V.-D.; Tran, C.Q.; Ko, S.-H.; Choi, H.-S. Dry plasma reduction to synthesize supported platinum nanoparticles for flexible dye-sensitized solar cells. J. Mater. Chem. A 2013, 1, 4436. [CrossRef]

11. Mohan, J.C.; Praveen, G.; Chennazhi, K.; Jayakumar, R.; Nair, S. Functionalised gold nanoparticles for selective induction ofin vitroapoptosis among human cancer cell lines. J. Exp. Nanosci. 2013, 8, 32-45. [CrossRef]

12. Dao, V.-D.; Vu, N.H.; Yun, S. Recent advances and challenges for solar-driven water evaporation system toward applications. Nano Energy 2019, 68, 104324. [CrossRef]

13. Dao, V.-D.; Vu, N.H.; Dang, H.-L.T.; Yun, S. Recent advances and challenges for water evaporation-induced electricity toward applications. Nano Energy 2021, 85, 105979. [CrossRef]

14. Cocean, I.; Cocean, A.; Postolachi, C.; Pohoata, V.; Cimpoesu, N.; Bulai, G.; Iacomi, F.; Gurlui, S. Alpha keratin amino acids BEHVIOR under high FLUENCE laser interaction. Medical applications. Appl. Surf. Sci. 2019, 488, 418-426. [CrossRef]

15. Cook, M.M.; Lander, J.A. Use of Sodium Borohydride to Control Heavy Metal Discharge in the Photographic Industry. J. Appl. Photogr. Eng. 1979, 5, 144-147.

16. Cotton, F.A.; Wilkinson, G. Advanced Inorganic Chemistry, 4th ed.; Interscience: New York, NY, USA, 1980.

17. Alonso, J.; Diamant, R.; Castillo, P.; Acosta-García, M.; Batina, N.; Haro-Poniatowski, E. Thin films of silver nanoparticles deposited in vacuum by pulsed laser ablation using a YAG:Nd laser. Appl. Surf. Sci. 2009, 255, 4933-4937. [CrossRef]

18. Gurlui, S.; Pompilian, G.O.; Nemec, P.; Nazabal, V.; Ziskind, M.; Focsa, C. Plasma Diagnostics in Pulsed Laser Deposition of GaLaS Chalcogenides. Appl. Surf. Sci. 2013, 278, 352-356.

19. Bechtel, J.H. Heating of solid targets with laser pulses. J. Appl. Phys. 1975, 46, 1585-1593. [CrossRef]

20. Kuznetsov, I.A.; Garaeva, M.Y.; Mamichev, D.A.; Grishchenko, Y.V.; Zanaveskin, M.L. Formation of ultrasmooth thin silver films by pulsed laser deposition. Crystallogr. Rep. 2013, 58, 739-742. [CrossRef]

21. König, J.; Nolte, S.; Tünnermann, A. Plasma evolution during metal ablation with ultrashort laser pulses. Opt. Express 2005, 13, 10598. [CrossRef]

22. Stafe, M.; Negutu, C.; Puscas, N.N.; Popescu, I.M. Pulsed laser ablation of solids. Rom. Rep. Phys. 2010, 62, 758-770.

23. Mercadier, L.; Hermann, J.; Grisolia, C.; Semerok, A. Analysis of deposited layers on plasma facing components by laser-induced breakdown spectroscopy: Towards ITER tritium inventory diagnostics. J. Nucl. Mater. 2011, 415, S1187-S1190. [CrossRef]

24. Stafe, M.; Vladoiu, I.; Negutu, C.; Popescu, I.M. Experimental investigation of the nanosecond laser ablation rate of aluminum. Rom. Rep. Phys. 2008, 60, 789-796.

25. Gurlui, S.; Sanduloviciu, M.; Strat, M.; Strat, G.; Mihesan, C.; Ziskind, M.; Focsa, C. Dynamic space charge structures in high fluence laser ablation plumes. J. Optoelectron. Adv. Mater. 2006, 8, 148-151.

26. Gurlui, S.; Agop, M.; Nica, P.; Ziskind, M.; Focsa, C. Experimental and Theoretical Investigations of a Laser Produced Aluminum. Plasma Phys. Rev. E 2008, 78, 026405. [CrossRef]

27. Cocean, A.; Cocean, I.; Gurlui, S.; Iacomi, F. Study of the pulsed laser deposition phenomena by means of Comsol Multiphysics. Univ. Politeh. Buchar. Sci. Bull. Ser. A Appl. Math. Phys. 2017, 79, 263-274.

28. Pretsch, E.; Buhlmann, P.; Badertscher, M. Structure Determination of Organic Compounds, 4th ed.; Revised and Enlarged Edition; Springer: Berlin/Heidelberg, Germany, 2009. [CrossRef]

29. Miller, F.A.; Wilkins, C.H. Infrared Spectra and Characteristic Frequencies of Inorganic Ions. Anal. Chem. 1952, $24,1253-1294$. [CrossRef]

30. Durdureanu-Angheluta, A.; Mihesan, C.; Doroftei, F.; Dascalu, A.; Ursu, L.; Velegrakis, M.; Pin-teala, M. Formation by laser ablation in liquid (lal) and characterization of citric acid-coated iron oxide nanoparticles. Rev. Roum. Chim. 2014, 59, 151-159.

31. Galazzi, R.; Santos, E.; Caurin, T.; Pessoa, G.; Mazali, I.; Arruda, M.A.Z. The importance of evaluating the real metal concentration in nanoparticles post-synthesis for their applications: A case-study using silver nanoparticles. Talanta 2016, 146, 795-800. [CrossRef]

32. Li, Y.; Ye, Y.; Fan, Y.; Zhou, J.; Jia, L.; Tang, B.; Wang, X. Silver Nanoprism-Loaded Eggshell Membrane: A Facile Platform for In Situ SERS Monitoring of Catalytic Reactions. Crystals 2017, 7, 45. [CrossRef]

33. Choi, B.-H.; Lee, H.-H.; Jin, S.; Chun, S.; Kim, S.-H. Characterization of the optical properties of silver nanoparticle films. Nanotechnology 2007, 18, 075706. [CrossRef]

34. Jia, H.; Xu, W.; An, J.; Li, D.; Zhao, B. A simple method to synthesize triangular silver nanoparticles by light irradiation. Spectrochim. Acta 2006, 64, 956-960. [CrossRef]

35. Paramelle, D.; Sadovoy, A.; Gorelik, S.; Free, P.; Hobley, J.; Fernig, D. A rapid method to estimate the concentration of citrate capped silver nanoparticles from UV-visible light spectra. Analyst 2014, 139, 4855-4861. [CrossRef]

36. Maillard, M.; Huang, P.; Brus, L. Nano-Silver Nanodisk Growth by Surface Plasmon Enhanced Photoreduction of Adsorbed [Ag+ ${ }^{+}$. Nano Lett. 2003, 3, 1611-1615. [CrossRef] 
37. Ahern, A.M.; Garrell, R.L. In situ photoreduced silver nitrate as a substrate for surface-enhanced Raman spectroscopy. Anal. Chem. 1987, 59, 2813-2816. [CrossRef]

38. Djokić, S. Synthesis and Antimicrobial Activity of Silver Citrate Complexes. Bioinorg. Chem. Appl. 2008, 2008, 436458. [CrossRef]

39. Molon, M.; Zebrowski, J. Phylogenetic relationship and FTIR spectroscopy-derived lipid determinants of lifespan parameters in the Saccharomyces cerevisiae yeast. FEMS Yeast Res. 2017, 17. [CrossRef] [PubMed]

40. Galichet, A.; Sockalingum, G.D.; Belarbi, A.; Manfait, M. FTIR spectroscopic analysis of Saccharomyces cerevisiae cell walls: Study of an anomalous strain exhibiting a pink-colored cell phenotype. FEMS Microbiol. Lett. 2001, 197, 179-186. [CrossRef] [PubMed]

41. Sucrose. Available online: https://webbook.nist.gov/cgi/cbook.cgi?ID=C57501\&Type=IR-SPEC\&Index=0 (accessed on 4 September 2021).

42. ATR-FT-IR Spectrum of Sucrose (4000-225 $\left.\mathrm{cm}^{-1}\right)$. Available online: https://spectra.chem.ut.ee/paint/binders/sucrose/ (accessed on 4 September 2021). 